\title{
A determination of the synthetic hyetograph parameters for flow capacity assessment concerning stormwater systems
}

\author{
Karolina Mazurkiewicz ${ }^{1, *}$, and Marcin Skotnicki $^{1}$ \\ ${ }^{1}$ Institute of Environmental Engineering, Poznań University of Technology, P1. M. Skłodowskiej- \\ Curie 5, Poznań, Poland
}

\begin{abstract}
The paper presents the results of an analysis of the influence of synthetic rainfall duration and location of rainfall intensity peak on the rate of the flood volume in surcharged storm sewers. The analyzed rainfalls had durations from 15 minutes to 180 minutes. It was assumed, that the rainfall peak location would change between the beginning and the end of the rainfall with increments of $10 \%$ of the rainfall duration. Outflow simulations were performed with the use of SWMM5.1.012 for three models of real urban catchments with surfaces from $1.6 \mathrm{~km}^{2}$ to $6.7 \mathrm{~km}^{2}$. An assessment of the influence of rainfall parameters was made on the basis of the flood volume rates. Short rainfalls with peaks located at the beginning of rainfall duration do not generate flooding. For other rainfalls it was found that for a specified rainfall duration the flood volume increases with the increase of time of the rainfall peak location. The maximum flood volume varied from $5 \%$ to $12 \%$ of the total runoff volume, depending on the catchment area, and is generated by the rainfall, whose intensity peak occurs right after the time corresponding to the flow time through the catchment.
\end{abstract}

\section{Introduction}

One of the main uses of stormwater sewer system simulation models is the assessment of flooding risk, required by European Regulations EN 752 [1]. For this type of calculation, it is necessary to analyze the outflow from the catchment under pressurized flow conditions. The flows for water levels above the crown of the sewer can be calculated by using the mathematical model of unsteady flow, implemented in computer programs $[2,3]$.

The network capacity can be identified with the maximum flow in the sewers. The maximum flow is obtained by the greatest possible surcharge which corresponds to the surcharge at ground level. For the evaluation of network capacity, a series of historical heavy rainfalls, hyetographs developed with stochastic models or synthetic rainfalls can be used $[4,5]$. The use of synthetic rainfalls is most often required due to the lack of measured rainfall data for the concerned area. Usually, the only available form of information about the rainfall characteristic are IDF curves or DDF curves, which describe the relationship

\footnotetext{
*Corresponding author: karolina.mazurkiewicz@put.poznan.p1
} 
between the rainfall intensity (or rainfall depth), its duration and frequency of occurrence [6]. Directly from the IDF or DDF curve a "block rainfalls" (rainfalls with a constant intensity) can be developed. These kinds of rainfalls, however, are not useful in simulating outflow from the urban catchment due to significant underestimation of the outflow. In simulation models the variability of rainfall intensity over time should be considered [7, 8]. This variability can be represented by synthetic hyetographs consisting of a sequence of pulses with a constant intensity during the pulse. The total rainfall depth for the hyetograph with a specified duration corresponds to the value read from the IDF or DDF curves for this rainfall duration. Among the most popular and mainly used synthetic hyetographs are the Chicago hyetograph [9] and Euler type II [4]. The design of the Chicago hyetograph allows changing the location of maximum intensity (peak); in the case of Euler hyetographs the location of rainfall peak is constant and corresponds to $30 \%$ of the total rainfall duration. The advantage of Euler hyetographs over Chicago hyetographs is a very simple design any form of IDF or DDF curves can be used. In the case of Chicago hyetographs, the IDF or DDF curve must be described by a specific equation [10].

The results presented in the literature indicate that the average location of the maximum rainfall intensity is variable and range from $20 \%$ to $50 \%$ of the total rainfall duration [ 11 , 12]. Synthetic rainfalls should represent the properties of real rainfalls, hence the design of synthetic hyetographs should allow changing the location of maximum rainfall intensity. By changing the peak location in rainfall with a specified duration and depth according to IDF or DDF curves, different values of outflow characteristics can be obtained. For rainfalls with relatively small intensities during runoff from an impervious area, different values of maximum outflow and flood volume (volume of water which overflows above ground level) are obtained. For rainfalls with high intensities causing runoff from a pervious area, the change of rainfall peak location may additionally change the total volume of the outflow. This is one of the basic disadvantages of using synthetic rainfalls. Due to a lack of linear rainfall-runoff transformation, the rainfall frequency of occurrence will not always be equal to the outflow frequency of occurrence [13, 14]. From the IDF or DDF curves the total rainfall depth for a rainfall of a specified duration and frequency of occurrence is read. It means that the rainfall frequency of occurrence describes only one rainfall characteristic - this frequency can be attributed to only one selected characteristic. This selected characteristic should achieve a maximum value for a specified rainfall depth. This assumption allows identifying the rainfall frequency of occurrence with an outflow frequency of occurrence and justifying the use of synthetic rainfalls.

The aim of the presented analysis is the assessment of the influence of synthetic hyetograph parameters, represented by the rainfall duration and peak location, on the results of the evaluation of stormwater sewer system capacity. Knowledge of the relationship between rainfall and runoff parameters can allow clarification of the recommendations concerning choosing hyetograph parameters for simulations of runoff from urban catchment.

\section{Methods and Materials}

\subsection{Catchments}

The runoff calculations were made for three existing urban catchments located in Bydgoszcz and Poznań (fig. 1). The catchments A and B have a total area not exceeding 200 ha (tab. 1). This value is claimed as a boundary for stormwater sewer systems whose operation should be verified with the use of simulation models [4]. The catchment $\mathrm{C}$ with 
an area of approximately 670 ha is an example of a large and well-developed stormwater sewer system for Polish conditions.

a)

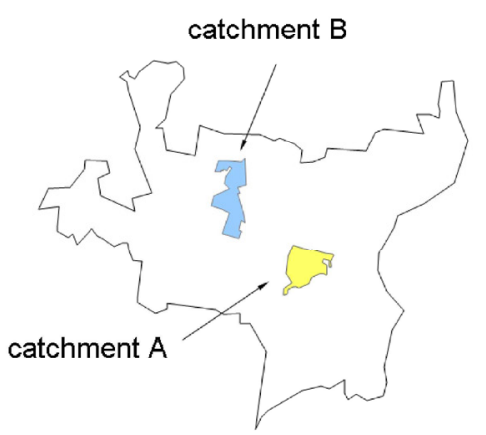

b)

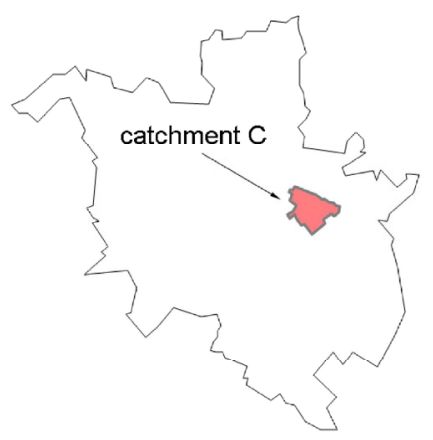

Fig. 1. The location of analyzed catchments: a) catchments A i B in Bydgoszcz; b) catchment C in Poznań (city plans without scale).

Storm Water Management Model 5.1.012 was used for the runoff simulation [15]. This program is widely used for the hydrodynamic modeling of stormwater systems. The models of catchments A and B were developed by the company Miejskie Wodociagi i Kanalizacja (MWiK) in Bydgoszcz as part of the stormwater system modernization program. The model of catchment $\mathrm{C}$ was made by the Poznań University of Technology [16]. Due to data availability this model is characterized with a much greater degree of simplification of network structure and subcatchment division.

Table 1. Chosen characteristics of analyzed catchments and their models.

\begin{tabular}{|c|c|c|c|c|}
\hline $\begin{array}{c}\text { Catchment } \\
\text { description }\end{array}$ & $\begin{array}{c}\text { Total } \\
\text { area } \\
\boldsymbol{F} \text { [ha] }\end{array}$ & $\begin{array}{c}\text { The longest } \\
\text { flow time } \\
\boldsymbol{T}_{\mathrm{F}}[\mathrm{min}]\end{array}$ & $\begin{array}{c}\text { Number } \\
\text { of subcatchments } \\
\text { in the model }\end{array}$ & $\begin{array}{c}\text { Number } \\
\text { of sewers } \\
\text { in the model }\end{array}$ \\
\hline $\mathrm{A}$ & 172 & 34 & 218 & 419 \\
\hline $\mathrm{B}$ & 157 & 86 & 176 & 272 \\
\hline $\mathrm{C}$ & 670 & 53 & 55 & 82 \\
\hline
\end{tabular}

In Table 1 , the longest flow time through the catchment $T_{F}$ (which includes the flow time through the sewers from the start node to the outfall) is presented. The flow time $T_{F}$ represents the catchment size, which is used for choosing the duration of a design storm. The calculation of $T_{F}$ was made on the basis of the Manning Formula, assuming uniform flow and full flow conditions and network parameters (sewer slopes and roughness coefficients) according to simulation models [17].

The models of catchments $\mathrm{A}$ and $\mathrm{C}$ were calibrated on the basis of a comparison of the simulation results for selected real rainfalls with the results of measurements. Data for catchment A were derived from the rainfall and runoff monitoring network, operated by $\mathrm{MWiK}$ in Bydgoszcz. The rainfall and runoff monitoring for catchment $\mathrm{C}$ was performed by The Institute of Environmental Engineering at the Poznań University of Technology. The calibration was made for the rainfalls causing free surface flows in sewers. Differences between the simulated and registered peak flows and the values of outflow volume were $\pm 15 \%$. These values were considered as acceptable and meeting the requirements concerning storm water system simulation models [18]. 


\subsection{Rainfalls}

The aim of the presented analysis includes the assessment of stormwater sewer system capacity. To achieve this aim, it is necessary to calculate the outflow under pressurized flow conditions, when the maximum level of surcharge is at ground level. It is not possible to accurately determine the rainfal depth generating pressurized flow under the assumed conditions. In the presented analysis rainfalls with the frequency of occurence $c=3$ years were used. These rainfalls are used for the assessment of surcharge frequency [4]. Rainfalls with the $c=3$ years have the lowest rainfall depth, which is causing pressurized flow conditions with a probability of negligible flooding (overdamming above groud level) and do not generate significant runoff from a pervious area, which could impede the assessment of results.

The analysis was made for synthetic rainfalls with durations $T_{D}$ from $15 \mathrm{~min}$ to $180 \mathrm{~min}$ (the durations increased by $5 \mathrm{~min}$ ). The longest considered rainfall duration corresponds to double flow time through the catchment $\mathrm{B}$, which has the greatest value of $T_{F}(\mathrm{tab} .1)$. The design rainfall duration equal to double flow time through the catchment is recommended for calcuating the outflow from the urban catchment [19]. To determine the location of maximum rainfall intenisty the ratio $r$ was used [9]. The ratio $r$ is the dimensionless time to rainfall peak $T_{P}$ related to the rainfall duration $T_{D}$. The considered values of ratio $r$ varied from 0 to 1 with the increment of 0.1 . Synthetic hyetographs for different values of rainfall duration and ratio $r$ were developed - the total number of developed hyetographs was 374 .

The rainfall depths for specific rainfall durations were calculated with the use of the Bogdanowicz-Stachy Formula [6], which is the form of DDF curve for Polish conditions. Due to the simple transformation of the DDF curve into the synthetic hyetograph, it was decided that the design of the synthetic hyetograph would be based on the Euler type II. Developing this kind of hyetograph is divided into two main stages. First, on the basis of the DDF curve, the rainfall depth increments for the assumed time intervals (corresponding to the time step of hyetograph discertization) are calculated. For each time step the temporary rainfall intensity is computed (fig. 2a). This temporary rainfall intensity represents a single rainfall pulse. At the second stage, the pulse with the maximum rainfall intensity (the peak) is located at $30 \%$ of the total rainfall duration (fig. $2 \mathrm{~b}$ ) and the next lower intervals are joined on to the left of this peak until the time $T_{D}=0$ is reached. Further rainfall intervals are joined onto the right of the peak until the end of the rainfall duration [4].

a)

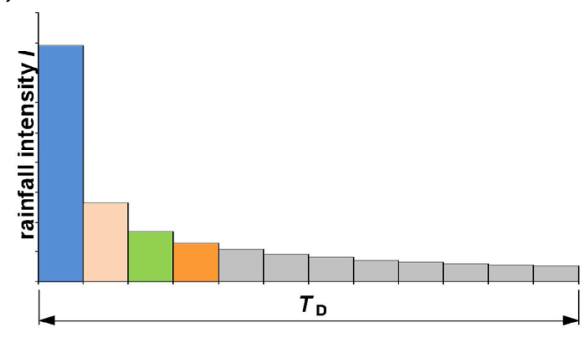

b)

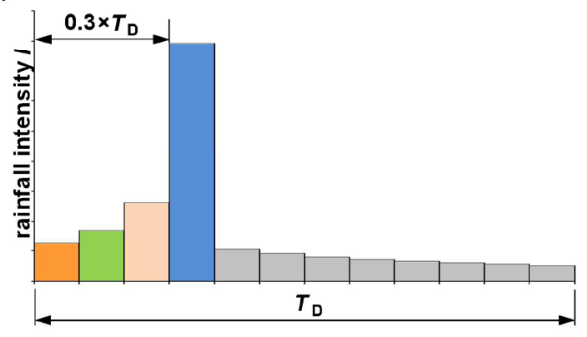

Fig. 2. The stages of Euler hyetograph type II design: a) calculating the temporary rainfall intensities on the basis of DDF curve, b) location of the peak at $30 \%$ of total rainfall duration.

For developing hyetographs with the peak location different than $30 \%$ of the total rainfall duration (according to assumed range of ratio $r$ ), a procedure similar to original Euler hyetograph was maintained- the next lower intervals were joined onto the left of rainfall peak until $T_{D}=0$ was reached (fig. 3). The Bogdanowicz-Stachy Formula can be 
used for a minimum rainfall duration of 5 minutes. According to this fact it was decided that the pulse with the maximum rainfall intensity would last 5 minutes. The remained rainfall pulses had time intervals of $1 \mathrm{~min}$, which allowed an accurate determination of the rainfall peak location. The rainfall peak was located at the beginning of the pulse with the maximum intensity.

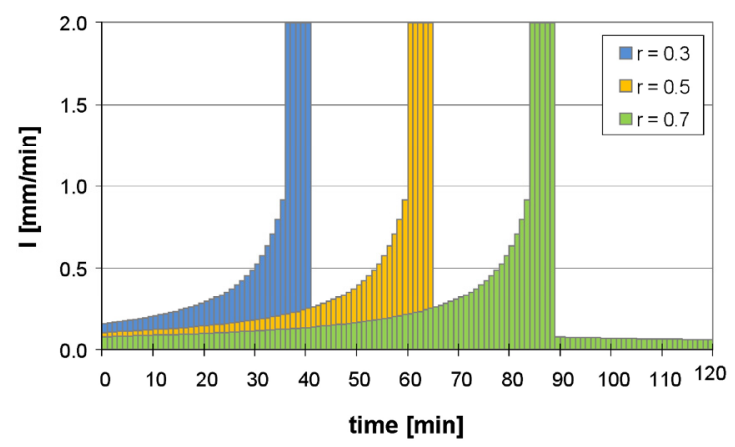

Fig. 3. Examples of hyetographs for the specified $T_{D}(120 \mathrm{~min})$ and different values of ratio $r(0.3,0.5$ and 0.7 ).

\subsection{The scope of the analysis}

It should be expected that for the analyzed catchments the rainfalls with the frequency of occurence of $c=3$ years can cause insignificant flooding. It particularly concerns catchment B, which was not calibrated. In the case of flooding (surcharge above ground level) the maximum outflow in the selected cross section cannot be a reliable value, because it can be disrupted by the flooding which occurs in the considered cross sectionthe hydrograph shape during the flooding is deformed as an effect of the flattening of the hydrograph peak. When the surcharge is above ground level and continuing the increase of rainfall intensity causing an increase of the runoff, it will not affect the value of maximum outflow in considered cross section.

According to this fact, the value of flood volume $V_{F}$ was chosen to assess the influence of the rainfall parameters on the outflow. This allows a comparison of the results achieved for all the considered catchments. The flood volume $V_{F}$ is presented as a dimensionless value related to the total runoff for a specified rainfall.

\section{The results and the discussion}

The maximum value of flood volume $V_{F}$ varied from $5 \%$ of the total runoff in the case of catchment A to $12 \%$ for catchment B (fig. 4). The significantly greater value of $V_{F}$ for catchment $\mathrm{B}$ is probably the result of the lack of calibration of this catchment model. In general, greater values of flood volume can be an effect of inaccurate assessment of catchment parameters, especially the effective impervious area. The value of effective impervious area in the model can be overestimated, which results in higher runoff values than in real conditions.

The greatest values of flood volume $V_{F}$ for the synthetic hyetograph with ratio $r=0.3$ (corresponding to the basic peak location in Euler type II) varied from $4 \%$ to $8 \%$, depending on the catchment (fig. 4). These values are approximately $25 \%$ lower than the maximum flood volumes obtained for rainfalls with greater ratio $r$. Therefore, it is one of the reasons for considering the variability of rainfall peak during the simulation of runoff from an urban catchment. 

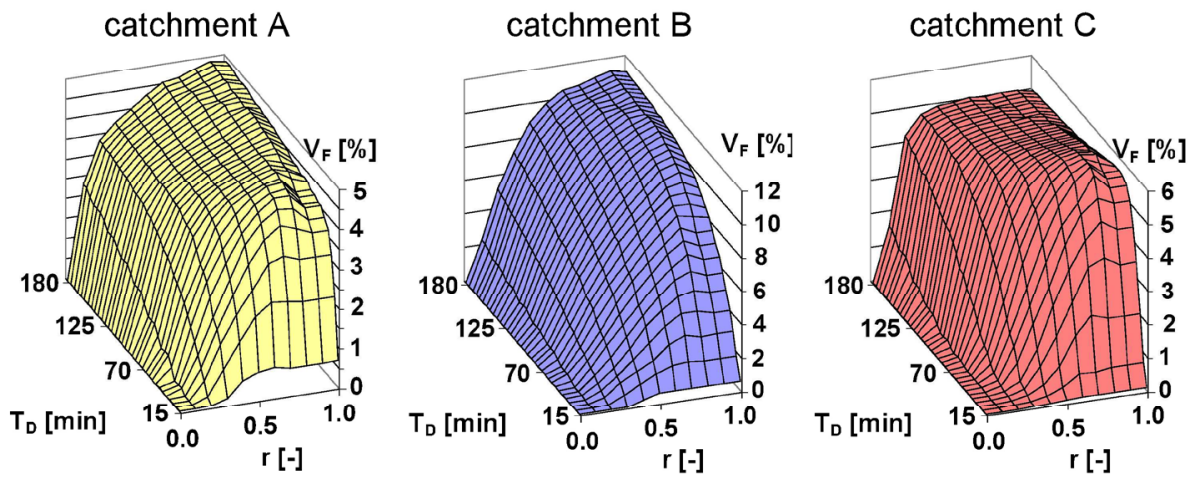

Fig. 4. The changes of flood volumes as a function of rainfall duration $T_{D}$ and ratio $r$.

Regardless of the catchment characteristics, a significant relation between flood volume $V_{F}$ and rainfall parameters $\left(r\right.$ and $\left.T_{D}\right)$ was observed. The differences, discussed in detail in the further part of this publication, may be the result of individual characteristics of the catchments and their models.

For the hyetographs with a peak location at the beginning of the rainfall $(r=0)$ flooding does not occur. In the initial phase of the rainfall-runoff transformation, a part of the rain is intercepted at the catchment area as a result of surface retention. If the peak occurs at the beginning of the precipitation, surface retention reduces the intensity peak and as a result, the surface runoff is generated by the smaller rainfall depth. According to the accepted hyetograph design, the shape of the synthetic rainfall for $r=0$ is the same for all analyzed rainfall duration $T_{D}$. It corresponds to the first stage of the hyetograph development (fig. 2a). With an increase in the rainfall duration, only a part of hyetograph with decreasing intensities is prolonged. Therefore, an increase in rainfall duration does not change the maximum outflow and, as a result, the flood volume. For short rainfall durations - up to 30 minutes (for the catchment areas $\mathrm{A}$ and $\mathrm{C}$ ) a maximum value for $V_{F}$ is generated by a rainfall with $r=0.7$. For rainfalls with a duration up to 60 minutes, the value of ratio $r$ generating a maximum outflow volume increases to 0.8 . For longer rainfall durations the maximum value for $V_{F}$ is obtained for rainfalls with $r=0.9$. Similarly for catchment (B) the rainfall durations with increasing ratio $r$ are respectively $40 \mathrm{~min}$ and $80 \mathrm{~min}$. For the peak location at the end of rainfall duration $(r=1.0)$ there has been a slight decrease in the flood volume. This is probably the result of the lack of a hyetograph part with decreasing intensities and, as a consequence, the reduced runoff to the sewer after the end of the rainfall peak in comparison with the hyetographs with a part of the decreasing intensities.

In conclusion, for a given rainfall duration a maximum flood volume is obtained for the ratio $r$ greater than 0.5 . Mentioned in the introduction, results concerning real rainfalls indicate that the greatest value of mean ratio $r$ does not exceed $0.5[11,12,16]$. Taking into account that synthetic rainfalls should represent the parameters of real rain, for practical use a rainfall with the highest $r$ values for real rain, that is $r=0.5$, should be recommended.

In the case of a constant value of ratio $r$, greater than zero, an increase of the rainfall duration $T_{D}$ causes an increase in the flood volume $V_{F}$ (fig. 4). After reaching a certain value of rainfall duration, called the threshold time $T_{D T}$, the flood volume does not change significantly and remains almost constant. The threshold time was assumed as rainfall duration with a specified value of ratio $r$ for which the maximum flood volume $V_{F}$ has been obtained. This maximum flood volume was determined as the real maximum value (as for the catchment $\mathrm{C}-$ fig. $4 \mathrm{c}$ ) or the value which subsequent increments of the volume does 
not exceed $0.5 \%$ of the total runoff volume (catchments A and B - fig. 4). The threshold increment of flood volume $(0.5 \%)$ corresponds to the accuracy of the simulation results, represented by the convergence error of a mass balance in relation to the volume of the outflow. The values of threshold time $T_{D T}$ for each catchment are presented in Table 2. In this table rainfalls with the ratio $r$ less than 0.3 were omitted. This value corresponds to the basic peak location in the hyetograph of Euler type II. Rainfalls with ratio $r$ lower than 0.3 generate relatively small flood volumes (fig. 4) and are therefore less important from a practical point of view. The main assumption in the use of synthetic rainfall concerns generating rain with a specified depth, the least advantageous flow conditions - the greatest maximum outflow and the greatest flood volume. For the same reason, in the analysis the rainfalls with the peak at the end of the rainfall duration $(r=1)$ were not considered. The flood volumes obtained for these rainfalls do not reach maximum values (fig. 4).

Table 2. The values of threshold times $T_{D T}$ and times to peak $T_{P}$ in hyetographs.

\begin{tabular}{|c|c|c|c|c|c|c|}
\hline \multirow[b]{2}{*}{$r[-]$} & \multicolumn{3}{|c|}{$T_{D T}[\mathrm{~min}]$} & \multicolumn{3}{|c|}{$T_{P}[\min ]$} \\
\hline & $\begin{array}{c}\text { catchment } \\
\text { A }\end{array}$ & $\begin{array}{c}\text { catchment } \\
\text { B }\end{array}$ & $\begin{array}{c}\text { catchment } \\
\text { C }\end{array}$ & $\begin{array}{c}\text { catchment } \\
\text { A }\end{array}$ & $\begin{array}{c}\text { catchment } \\
\text { B }\end{array}$ & $\begin{array}{c}\text { catchment } \\
\text { C }\end{array}$ \\
\hline 0.3 & 110 & $-(*)$ & 170 & 33 & $-(*)$ & 51 \\
\hline 0.4 & 85 & 180 & 155 & 34 & 72 & 62 \\
\hline 0.5 & 75 & 160 & 105 & 37.5 & 80 & 52.5 \\
\hline 0.6 & 75 & 145 & 80 & 45 & 87 & 48 \\
\hline 0.7 & 60 & 130 & 70 & 42 & 91 & 49 \\
\hline 0.8 & 55 & 120 & 60 & 44 & 96 & 48 \\
\hline 0.9 & 45 & 110 & 55 & 40.5 & 99 & 49.5 \\
\hline \multicolumn{4}{|c|}{ Mean $T_{P}$ [min] } & 39.4 & 87.5 & 51.4 \\
\hline \multicolumn{4}{|c|}{$T_{F}[\min ]($ tab. 1) } & 34 & 86 & 53 \\
\hline
\end{tabular}

$(*)$ - according to assumed criteria for $r=0.3$ the maximum value of flood volume was not reached

The threshold times decrease with the increase in ratio $r$. For the given catchment a value of time to peak $T_{P}$ is similar for all rainfalls and comparable with the flow time through the catchment $T_{F}$ (tab. 2). It indicates that for obtaining the greatest outflow from the catchment, represented in the analysis by the flood volume, it is necessary to choose the rainfall, whose peak is located in the time corresponding to the flow time through the catchment, regardless of the total rainfall duration. The result of the presented analysis extends the knowledge concerning choosing the duration of design rainfall for a simulation of runoff from the urban catchment. Recommendations available in the literature indicate the need for the selection of the rainfall duration only as a function of flow time through the catchment, regardless to the peak location [19]. Such an approach is not contrary to the presented results and gives a similar result; because extending the total rainfall duration $T_{\mathrm{D}}$ causes an increase in the time to peak $T_{P}$. However, depending on the shape of the hyetograph and its peak location, a design rainfall with variable total rainfall duration needs to be applied.

\section{Conclusions}

The results of the presented analysis allow formulating the following conclusions:

1. The maximum value of the runoff is generated by the synthetic rainfall with a specified time to peak, regardless to the total rainfall duration. 
2. Time to peak in the hyetograph that causes maximum outflow is similar to flow time through the catchment.

3. For practical use, a rainfall with ratio $r=0.5$ should be used during the modeling of maximum outflow from the urban catchment.

The authors would like to thank the Miejskie Wodociągi i Kanalizacja company in Bydgoszcz for sharing their catchment models and measurement data.

This work is made possible from resources of the Poznan University of Technology (01/13/DSPB/0856).

\section{References}

1. EN 752: Drain and sewer systems outside buildings. PKN, Warszawa (2008)

2. T. G. Schmitt, M. Thomas, N. Ettrich, J. of Hydrol., 299, 300-311 (2004)

3. D. S. Bisht, Ch. Chatterjee, S.Kalakoti, P. Upadhyay, M. Sahoo, A. Panda, Nat Hazards, 84, 749-776 (2016)

4. T. G. Schmitt: Kommentar zum Arbeitsblatt A 118 "Hydraulische Bemessung und Nachweis von Entwässerungssystemen” (in German), DWA, Hennef, (2000)

5. P. Licznar, J. Łomotowski, D. E. Rupp, Atm. Res. 99, 563-578 (2011)

6. E. Bogdanowicz, J. Stachý: Heavy Rainfalls in Poland (in Polish), IMGW, Warszawa, (1998)

7. L. Alfieri, F. Laio, P. Claps, Hydr. Proc. 22, 813-820 (2008)

8. N. El-Jabi, S. Sarrat, J. of Hydr. Eng., 117 (5), 681-685 (1991)

9. C. J. Keifer, H. H. Chu, ASCE J. of the Hydr. Div., 83 (HY4), 1-25 (1957)

10. A. L. L. da Silveira, Bras. J. of Water Res., Porto Alegre, v. 21, n. 3, 646-651 (2016)

11. V. Arnell: Rainfall data for the design of sewer pipe systems; with the supplement: Description and Validation of the CTH-Urban Runoff Model, Report Series A:8, Chalmers University of Technology, Dept. of Hydraulics, Goteborg, Sweden (1982)

12. P. Urcikán, J. Horváth, Water Sci. and Tech. Vol. 16 No 8-9, 69-83, (1984)

13. B. J. Adams, C. D. D. Howard, Canad. Water Res. J., 11:3, 49-55 (1986)

14. A. Vigilone, G. Blöschl, Hydrology and Earth System Sciences, 13, 205-216, (2009)

15. L. A. Rossman: Storm Water Management Model User's Manual Version 5.1, 09.2015, www.epa.gov/water-research/storm-water-mamagement-model-swmm (2015)

16. K. Mazurkiewicz : Determining the model-based rainfall characteristics for modelling the runoff from urban catchment (in Polish), PhD Thesis, Poznań University of Technology, (2016)

17. ASCE: Design and Construction of Urban Stormwater Management Systems. ASCE Manuals and Reports of Engineering Practice No. 77, WEF Manual of Practice FD-20 (1992)

18. UDG: Code of Practice for the Hydraulic Modelling of Urban Drainage Systems Version 01, CIWEM, http://www.ciwem.org/groups/udg/ (2017)

19. B. Kaźmierczak, A. Kotowski: Verification of storm water drainage capacity in hydrodynamic modelling (in Polish), Wrocław University of Technology, (2012) 